\title{
Manufacturing of Medicate Chewing Gum Against Oral Pathogens by the Extract of Seeds of Lepidium sativum $L$.
}

\author{
Nidhal M Salih' ${ }^{1}$ and Ruaa J Kadhim ${ }^{2}$ \\ $1^{1}$ Food Science Department, Agriculture College, Baghdad University, Iraq \\ ${ }^{2}$ Food Science Department, Agriculture College, Baghdad University, Iraq \\ Correspondence Author: Nidhal M Salih, Food Science Department, Agriculture College, Baghdad University, Iraq. \\ Email: Nidhalspring@yahoo.com
}

Received date: 23 February 2019, Accepted date: 22 May 2019, Online date: 30 May 2019

Copyright: (C) 2019 Nidhal M Salih et al., This is an open-access article distributed under the terms of the Creative Commons Attribution License, which permits unrestricted use, distribution, and reproduction in any medium, provided the original author and source are credited.

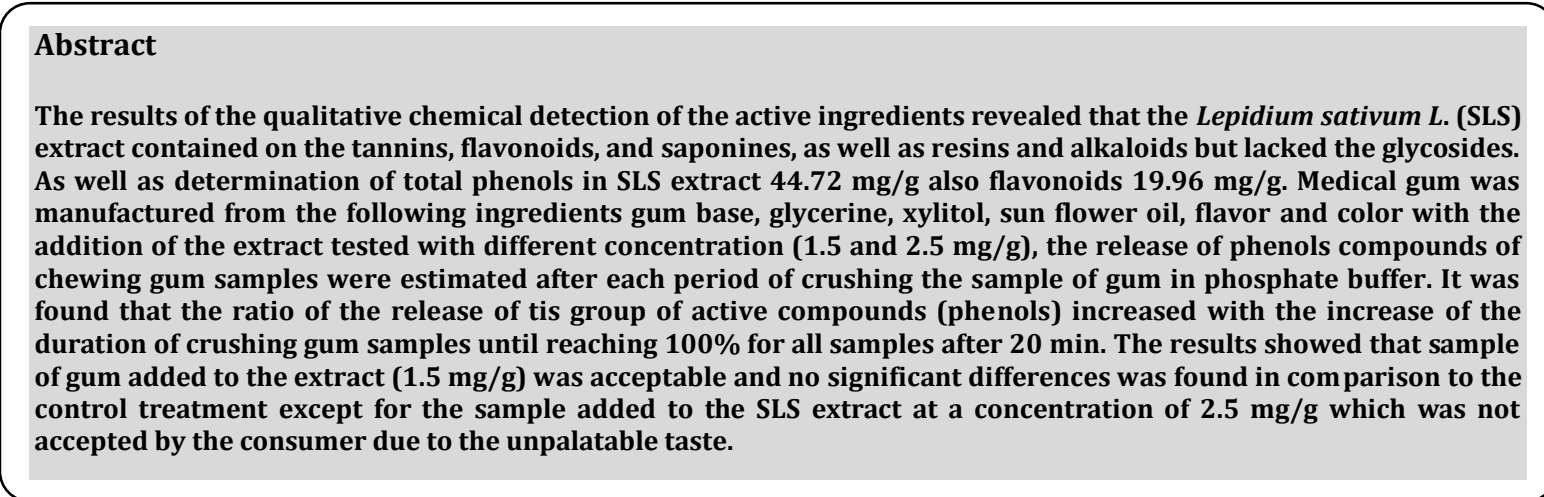

Keywords: Lepidium sativum L.,Phenols, Flavonoids, Chewing gum, phenol release

\section{INTRODUCTION}

Many plants have been used because of their antimicrobial traits, which are due to compounds synthesized in the secondary metabolism of the plant. These products are known by their active substances, for example, phenolic compounds, which are part of essential oils, tannins, terpenoids, alkaloids and flavonoids, these metabolites have been tested in vitro to have antimicrobial properties [1]. Various compounds in plants that are produced for self-protection could support each other in inhibiting bacterial growth, while also reducing the bacterial strains [2]. Chemotherapeutic agents from natural products have proved to be a promising source for the development of new drugs throughout human history [3]. Recently, several studies have shown the feasibility of using medicinal plants as a source of chemotherapeutic agents for the prevention of oral diseases [4].

Lepidium sativum L. (SLS) is a fast-growing edible herb which is due to family Brassicaceae (5). It has been reported that phytochemicals, which are considered as secondary products components, are directly responsible for an activity such as antioxidant, antimicrobial, antifungal, anticancer, and anti-inflammatory, among others [6].

Oral diseases are major health problems with dental caries and periodontal diseases among the most important preventable global infectious diseases. Struptococcus mutans, a member of endogenous oral microflora, has long been implicated to play a vital role in the pathogenesis of these diseases [7]. Dental caries prevention is preferable to treatment. Convention preventive methods, such as the use of alcohol or antibiotics, like chlorhexidine, erythromycin, ampicillin, and penicillin, have proven effective in preventing dental caries [8].

However, excessively used of these chemicals has been reported to change the oral and intestinal flora, and can cause other problems such as vomiting, tooth staining or oral cancer, importantly antibacterial agents can also promote the development of 
resistant bacteria strains [9,10]. For these reasons, alternative methods such as the use of medicinal plants are of increasing interest.

In recent years, research is developing new methods of dental disease prevention, releasing natural bioactive compounds included in traditional or innovative medical devices in the mouth to improve tooth protection. Chewing gums is a particularly useful means for delivering and maintaining bioactive compounds, included in the gum formulation able to have an anti-cariogenic effect [11] Gum advantages over the other delivery methods include no needing to water or liquids to eat, increasing the systemic effects, low dose administration, faster onset of action and good stability relieving of dry mouth strengthening the mastication muscles and prevention of dental caries [12]. In the present study apply different concentrations from the SLS extracts in the manufacturing of medicating gum to protect teeth from the effect of the bacteria and thus prevent teeth decay.

\section{MATERIALS AND METHODS}

\section{Plants collection}

The seeds of Lepidium sativum L. (SLS) were purchased from the local market for herbs in Baghdad. After that these seeds were grounded into powder, and kept till use.

\section{Extraction}

The applied method according to the method described by [13] to $10 \mathrm{~g}$ of the extract powder of LSL added $300 \mathrm{ml}$ of distilled water at boiling point and the mixture was left for $30 \mathrm{~min}$ on a magnetic stirrer. After that, the mixture was filtered through filter paper (What man No.1), then concentrated by rotary evaporator under reduced pressure at $50^{\circ} \mathrm{C}$, the concentrated extracts were dried in the oven at $40^{\circ} \mathrm{C}$, scraped and stored the powder in labeled sterile screw-capped bottles at $5^{\circ} \mathrm{C}$ in the refrigerator, until when required for use.

\section{Phytochemical screening}

The aqueous extract were subjected to various chemical tests in order to estimate the active compounds by employing multiple methods described by [14] which are reported in [15] for detection of glycosides, tannins, flavonoids and saponins, while employing the method mentioned in [16] for alkaloids and [17] for steroids and terpenes.

\section{Determination of total phenolic compounds}

Folin-ciocalteu's reagent colorimetric method was used as described by [18] add $0.5 \mathrm{ml}$ of the extract (1 $\mathrm{mg} / \mathrm{ml})$ to $2.5 \mathrm{ml}$ of Folinciocalteu's reagent, and $2 \mathrm{ml}$ of sodium carbonate $7.5 \%$ then left the mixture for $30 \mathrm{~min}$ at room temperature, the absorbance was recorded at $760 \mathrm{~nm}$, the total phenolic compounds were determined according to gallic acid standard curve fig (1).

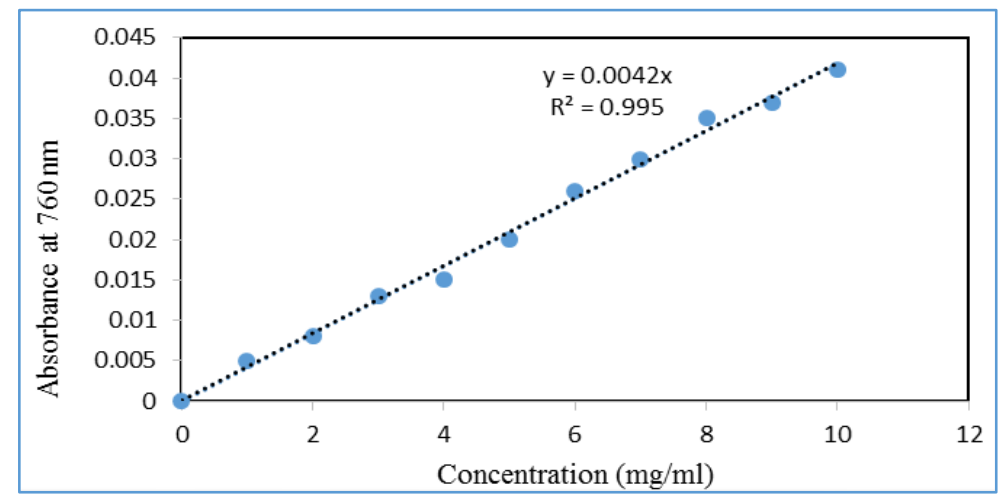

Figure 1: Standard curve of gallic acid

\section{Determination of total flavonoids compounds}

The total flavonoids in the aqueous extract were determined according to [19] mixing $1 \mathrm{ml}$ of the extracts $(1 \mathrm{mg} / \mathrm{ml})$ in a $10 \mathrm{ml}$ volumetric flask with $5 \mathrm{ml}$ of distilled water and $0.3 \mathrm{ml}$ of $\mathrm{NaNo}_{2} 5 \%$. After 5 min added $0.6 \mathrm{ml}$ of AlCl3 $10 \%$. After another $5 \mathrm{~min}$ added $2 \mathrm{ml}$ of $1 \mathrm{M} \mathrm{NaOH}$ and the volume was made up to $10 \mathrm{ml}$ with distilled water. The mixture was mixed thoroughly, and the absorbance was measured at $510 \mathrm{~nm}$. The total flavonoids compounds were determined according to catechin standard curve fig (2). 


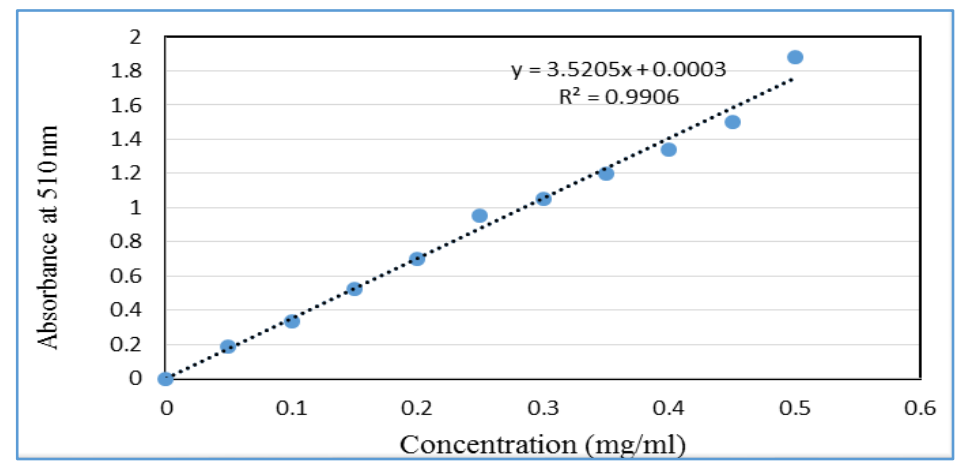

Figure 2: Standard curve of catechin

\section{Chewing gum preparation}

Chewing gum was formulated of the gum base, oil, glycerin, xylitol, color, and flavor. The combination of the base was softened in a water bath at $60^{\circ} \mathrm{C}$. Oil, glycerin, and xylitol, finally color and flavor and plant extract (1.5 and $\left.2.5 \mathrm{mg} / \mathrm{g}\right) \mathrm{were}$ added at 40 ${ }^{\circ} \mathrm{C}$ table (1). The homogeneous mixture was extended on a glass plate. Then it was cooled and cut in small pieces and kept for 48 hours at room temperature.

Table 1: Ingredient of medicated chewing gum

\begin{tabular}{|c|c|c|}
\hline No. & Ingredient & g \\
\hline 1 & Gum base & 75 \\
\hline 2 & Glycerine & 15 \\
\hline 3 & Xylitol & 1.5 \\
\hline 4 & Sun flower oil & 2.5 \\
\hline 5 & Flavor and color & 0.7 \\
\hline
\end{tabular}

\section{In vitro: phenol release test}

One gram of the formulation was taken in a mortar, added to it $50 \mathrm{ml}$ of $\mathrm{pH} 6.8,0.2 \mathrm{M}$ phosphate buffer and for 20 min crushed. The temperature was maintained at $37^{\circ} \mathrm{C}$ by a water bath. $0.5 \mathrm{ml}$ aliquots of the mixture were removed at the times of $0,5,10,15$ and 20 min since the start of crushed. The aliquots were replaced by $0.5 \mathrm{ml}$ fresh phosphate buffer subsequently. After that, added the solutions of total phenols determination ( $2.5 \mathrm{ml}$ folin-cicalteu's reagent and $2 \mathrm{ml}$ sodium carbonate $7.5 \%)$ and absorbance was recorded at $760 \mathrm{~nm}$ by using a spectrophotometer.

\section{Evaluating the organoleptic characteristics}

To evaluate organoleptic features of this product, ten healthy volunteers were asked to chew the gum and give comments on the hardness/softness, adhesion to teeth, the volume of the gum mass and taste according to the Likert scale on the evaluation forms (20) Table (2).

\begin{tabular}{|c|c|c|c|c|c|c|c|c|}
\hline \multirow{2}{*}{ No } & \multirow{2}{*}{ Organoleptic properties } & \multicolumn{7}{|c|}{ Samples } \\
\hline & & 1 & 2 & 3 & 4 & 5 & 6 & 7 \\
\hline 1 & Chewing gum volume & & & & & & & \\
\hline 2 & Softness & & & & & & & \\
\hline 3 & No adherence & & & & & & & \\
\hline 4 & Taste & & & & & & & \\
\hline 5 & Persistence of taste & & & & & & & \\
\hline
\end{tabular}

1. The bulk volume of gum was evaluated as Huge $=5$, much $=4$, right $=3$, little=2, very little $=1$.

2. The softness/Hardness was evaluated as very hard=5, hard=4, suitable $=3$, soft=2, very soft $=1$.

3. The adherence to the teeth was evaluated as never adheres $=5$, rarely adheres $=4$, sometimes adheres $=3$, often adheres $=2$, always sticks $=1$.

4. The taste was evaluated as excellent $=5$, good $=4$, fair $=3$, poor $=2$, very poor $=1$.

5. The persistence of the taste was evaluated as strong persistence $=5$, good persistence $=4$, intermediate persistence $=3$, weak persistence $=2$, very weak persistence $=1$

\section{Statistical analysis}

The Statistical Analysis System- SAS [21] program was used to show the effect of the difference of treatments in study parameters. The least significant difference - LSD ( $p>0.05)$ was used to significant compare between means in this study. 


\section{RESULTS AND DISCUSSION}

The phytochemical tests were done on aqueous extract, which was prepared from seeds of Lapidium Sativum L. (SLS). The results are summarized in table (3). Most of the active compounds were isolated and identified in the crude extracts of the plant [22]. Phytochemical screening of SLS extract presence of various medically active constituents, the phytochemical compounds present in the SLS extract is rich in tannins, flavonoids, saponins, and terpenes. On the other hand, they lack glycosides. Other researcher who has demonstrated the presence of flavonoids, alkaloids, and saponins, and absence of tannins, sterols, and polyterpenes in SLS extract [23]. The results of the phytochemical tests indicated that the plant possesses various biologically active compounds which could serve as a potential source of drugs in herbal medicine [24]. Phytochemicals such as saponins, terpenoids, flavonoids, tannins, steroids, and alkaloids have anti-inflammatory effects [25], glycosides, flavonoids, tannins, and alkaloids have hypoglycemic activities [26,27], steroids and triterpenoids showed the analgesic properties [28]. Total phenols and flavonoids content of SLS aqueous extract 44.72, $19.96 \mathrm{mg} / \mathrm{g}$, respectively.

Table 3: Phytochemical screening of aqueous extract of SLS

\begin{tabular}{|c|c|c|c|}
\hline Compounds & Detection & Detected indicator & Result of detection \\
\hline \multirow{2}{*}{ Tannins } & Lead acetate 1\% & White gel precipitate & + \\
\cline { 2 - 4 } & Ferric chloride 1\% & Bluish green & + \\
\hline Glycosides & Fehling indicator A, B & Red precipitate & - \\
\hline Flavonoids & Ethyl alcohol 95\%+ KOH & Yellow ring & ++ \\
\hline Saponins & Cold distilled water & Persistent foam & +- \\
\hline Resins & Ethyl alcohol 95\%+ boiling & Clear crumb & + \\
\hline \multirow{3}{*}{ Alkaloids } & Mayer's reagent & White precipitate & ++ \\
\cline { 2 - 4 } & Picric acid & Yellow precipitate & ++ \\
\cline { 2 - 4 } & Dragendrroff's reagent & Orange precipitate & ++ \\
\hline Stereol and terpenes & Chloroform+ anhydrous acid & Blue-black color & + \\
\hline
\end{tabular}

+/presence - /none detected

Fig (3) show the rate of release of phenols compounds found in the chewing gum to the phosphate buffer solution, which represents saliva in the manner of estimating phenols compounds. The results of the current study showed that the phenols release to the solution increased by crushing time of the chewing gum samples. The phenols release rate was 36.44 and $38.22 \%$ after 5 $\min$ at 1.5 and $2.5 \mathrm{mg} / \mathrm{g}$ respectively — all the tested formulations released approximately $100 \%$ of their active agents after 20 min. In general, the results showed that the samples of chewing gum with a higher concentration of extracts had a higher phenols release rate than the samples with a lower concentration. This may be due to the increased concentration of phenols polymerized in the high concentration of the extract. Phenols are either small molecules such as phenolic acids or high polymerization compounds such as tannins [29]. The drug-polymer ratio was found to affect the drug release characteristics of the prepared chewing gums, at higher drug-polymer ratio, the drug release from the chewing gums was faster as compared to lower drug polymer ratio, this was because the high drug-polymer ratio promotes the increase saliva uptake and lead to the greater solubilization of the drug present in the polymer matrix causing faster diffusion of drug through the gum base (30).

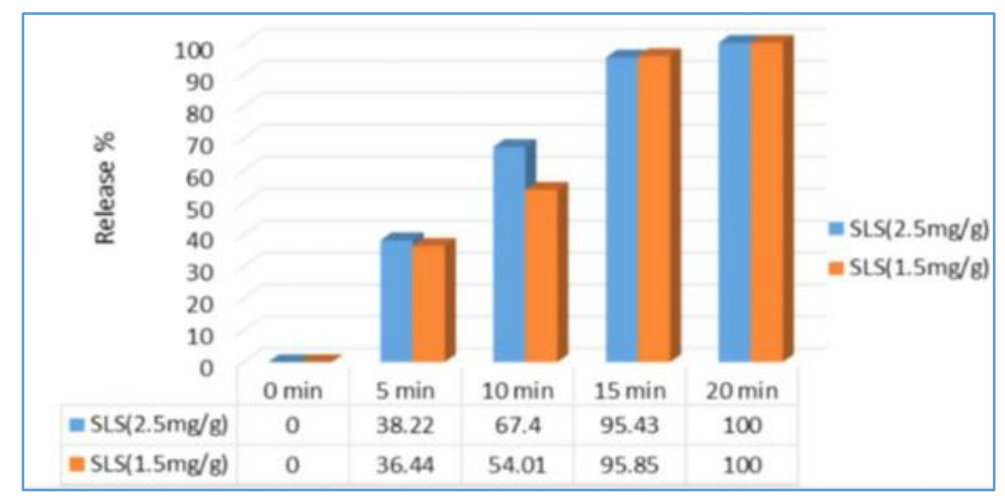

Figure 3: In vitro release of phenols from chewing gum formulations in $\mathrm{pH} 6.8$ phosphate buffer at $37{ }^{\circ} \mathrm{C}$ with various concentrations of SLS extract.

Shows the results of the statistical analysis of the organoleptic properties of the chewing gum, which are treated with different concentrations of the SLS extract compared with the control (without adding the extract). The results showed no significant differences $(\mathrm{p}<0.05)$ for the chewing gum samples added to the extract SLS $(1.5$ and $2.5 \mathrm{mg} / \mathrm{g})$ compared to the treatment of the control in the qualities of chewing gum volume, softness, hardness, no adherence and persistence of taste. As for the taste characteristic, there was no significant difference for the chewing gum samples added to the extract SLS (1.5 mg/g), while SLS $(3.0 \mathrm{mg} / \mathrm{g})$ had a significant difference $(\mathrm{p}<0.05)$ in taste compared to the control treatment. Fig (4) shows the resulting chewing gum forms for two treatment with control. 


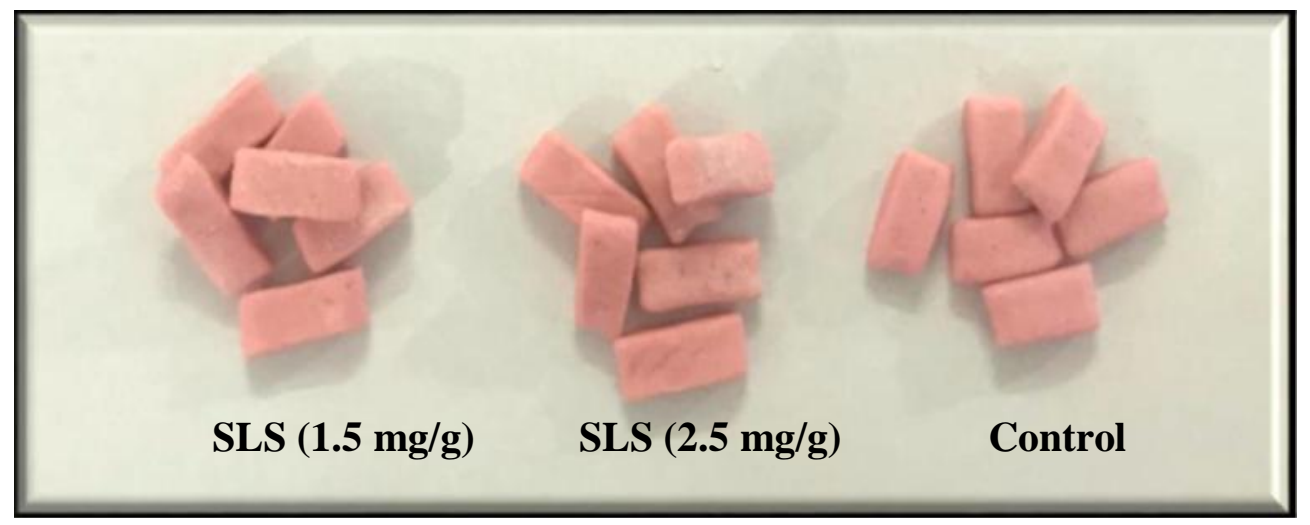

Figure (4): Experimental chewing gums produced

\section{REFERENCES}

1. Akrayi, H.F.S. and Tawfeeq, J.D. (2012). Antibacterial activity of LepidiumSativum and allium porrum extracts and juices against some gram positive and gram-negative bacteria. Medical Journal of Islamic World. Academy of Sciences, 20(1): 1016.

2. Chaiya, A.; Saraya, S.; Chuakul, W. and Temsirirkkul, R. (2013). Screening for dental caries: preventive activities of medicinal plants against Streptococcus mutans. Mahidol University Journal of Pharmaceutical Sciences, 40(1): 9-17.

3. Jeon, J. G. ;Rosalen, P. L.; Falsetta, M. L. and Koo, H. (2011). National products in caries research: Current (limited) knowledge, challenges and future perspective. Caries Res., 45: 243-263.

4. Ferrazzano, G. F.; Roberto, L.; Amato, I.; Cantile, T.; Sangianantoni, G. and Ingenito, A. (2011). Antimicrobial properties of green tea extract against cariogenic microflora: An in vivo study. J. Med. Food., 14: 907-911.

5. Bhasin, P.; Bansal, D.; Punia, A. and Sehrawat, A.R. (2012). Antimicrobial activities of LepidiumSatiovum: Medicinal plant used in folklore remedies in India. Journal of Pharmacy Research, 5(3): 1643-1645.

6. Kakate, K.C. (1997). 4th ed. Delhi: VallabhPrak-ashan; Practical Pharmacognocy, 21018.

7. Hasan, S.; Danishuddin, M.; Adil, M.; Singh, K.; Verma, P. K. and Khan, A. U. (2012). Efficacy of E.officinalis on the cariogenic properties of Streptococcus mutans: A novel and alternative approach to suppress quorum-sensing mechanism. PLOS One., 7: 40319.

8. Järvinen, H.; Tinovuo, J. and Huovinen, P. (1993). In vitro susceptibility of Streptococcus mutans to chlorhexidine and six other antimicrobial agents. Antimicrob Agents Chemother., 37(5): 1158-9.

9. Park, K.M.; You, J.S.; Lee, H.Y.; Back, N.I.; Hwang, J.K. and Kuanon, G. (2003). An antibacterial agent from the root bark of Morus alba against oral pathogens. J. Ethnofarmacol, 84(2-3): 181-5.

10. Chung, J.Y.; Choo, J.H.; Lee, M.H. and Hwang, J.K. (2006). Anticariogenic activity of macelignan isolated from Myristicafragrans (nutmeg) against Streptococcus mutans. Phytomedicine, 13(4): 261-6.

11. Ferrazano, G. F.; Cantile, T.; Coda, M.; Alcidi, B.; Sangianantoni, G.; Ingenito, A.; Stasio, M. D. and Volpe, M. G. (2016). In vivo release kinetics and antibacterial activity of novel polyphenols-enriched chewing gums. Molecules, 21 (1008): 1-11.

12. Aslani, A.; Ghannadi, A.; Mortazavi, S. and Torabi, M. (2013). Design, formulation and evaluation of medicinal chewing gum by the extract of SalvadoraPessica L. life Science Journal, 10(4): 47-55.

13. Pin-Der, D. and Gow-Chin, Y. (1997). Antioxidative activity of three herbal water extracts. Food Chemistry, 60 (4): $639-645$.

14. Shihata, I. M. A.(1951). Pharmacological study of Anagallisarvesis .M.D. Vet. Thesis-Cairo University.

15. Abdalla, A. E. M.; Darwish, S. M.; Ayade, E. and El-Hamahmy, R. M. (2007). Egyption mango by-product 2: Antioxidant and antimicrobial activities of extract and oil from mango seed kernel. Food Chemistry, 103: 1141-1152.

16. Fahmy, I. R. (1933). Constituents of plant crude drugs. Ist .Ed. PoulBarbey. Cairo.

17. Al-Bid, M. R. (1985). Zurrzusammemseturumgderabsehle membrane in phoenix dactylifera, Wuzzbury university, wazzburg F.R of Germany.

18. Ayoola, G. A. ; Ipav, S. S.; Sofidiya, M.O.; AdepojuBeello, A. A; Coker,H.A. and Odugbemi, T. O. (2008). Phytochmical Screening and free Radical Scavenging Activities of the Fruits and Leaves of AllanblackiafloribunaOliv (Guttiferae) . International Journal of Health Research, 1(2):87-93.

19. Rao, K. S.; Keshar, N. K. and Ravi, K.B. V. V. J. (2012). Microwave assisted extraction and evaluation of in vitro antioxidant activity of Cinnamomumaromaticum . Medicinal plants Research .6(3):439-448.

20. Aslani, A.; Ghanadi, A. and Rostami, F. (2016). Design, formation and evaluation of ginger medicated chewing gum. Adv Biomed Res., 5: 130.

21. SAS. (2012). Statistical analysis system, user's guide. Statistical. Version 9th ed. SAS. Inst. Inc. Cary. N. S., USA.

22. Suresh, S. N.; Nagarajan, N. (2009). Journal of Basic and Applied Biology, 3(1 and 2): 59-61.

23. Chatoui, K.; Talbaoui, A.; Aneb, M.; Bakri, Y.; Harhar, H. and Tabyaoui, M. (2016). Phytochemical screening, antioxidant and antibacterial activity of LepidiumSativum seeds from Morocco. J. Matter. Environ. Sci., 7(8): 2938-2946.

24. Capasso, A., Piacente, S. and Pizza, C. (1997). Isoquinoline alkaloids from Argemone Mexicana reduce morphine with rawal in guinea pig isolated ileum. PlantaMedica., 63(4): 326-8. 
25. Akindele, A.J. and Adeyemi, O.O. (2007). Anti-inflammatory activity of the aqueous leaf extract of Byrsocarpuscoccineus. Fitoterapia, 78: 25-28.

26. Oliver, B. (1980). Oral hypoglycaemic plants in West Africa. J. Ethnopharmacol, 2: 119-127.

27. Cherian, S. and Augusti, K.T. (1995). Insulin sparing action of leucopelargoniding derivative isolated from Ficusbengalesis Linn. Ind. J. Exp. Biol., 33: 608-611.

28. Rupasinghe, H.P.; Jackson, C.J.; Poysa, V.; Di, B.C.; Bewley, J.D. and Jenkinson, J. (2003). Soyasapogenol A and B distribution in Soybean (Glycine Max L. Merr) in relation to seed physiology, genetic variability and growing location. J. Agric. Food Chem., 51: 5888-5894.

29. D'Archivio, M.; Filesi, C.; Di Benedetto, R.; Gargiulo, R.; Giovannini, C.andMasella, R. (2007). Polyphenols, dietary sources and bioavailability. Ann. Ist. Super. Sanita ., 43: 348-361.

30. Lakshmi, S.V.; Yadav, H.K.S.; Mahesh, K.P.; Uniyal, S.; Ayaz, A. and Nagavarma, B.V.N. (2014). Formulation and evaluation of medicated chewing gum as antiplaque and antibacterial agent. Journal of Young Pharmacists, 6(4): 3-10. 